\title{
Self-Reported Health Status Predicts Other-Cause Mortality in Men with Localized Prostate Cancer: Results from the Prostate Cancer Outcomes Study
}

\author{
Richard M. Hoffman, MD, MPH ${ }^{1,2}$, Tatsuki Koyama, PhD ${ }^{3}$, Peter C. Albertsen, MD4, \\ Michael J. Barry, MD', Timothy J. Daskivich, MD', Michael Goodman, MD, MPH', \\ Ann S. Hamilton, PhD ${ }^{8}$, Janet L. Stanford, PhD ${ }^{9}$, Antoinette M. Stroup, PhD ${ }^{10}$, Arnold L. Potosky, PhD ${ }^{11}$, \\ and David F. Penson, MD, MPH ${ }^{3}$
}

\begin{abstract}
'University of New Mexico School of Medicine, Albuquerque, NM, USA; ${ }^{2}$ Albuquerque VA Medical Center, Albuquerque, NM, USA; ${ }^{3}$ Vanderbilt University, Nashville, TN, USA; ${ }^{4}$ University of Connecticut, Farmington, CT, USA; ${ }^{5}$ Harvard Medical School, Boston, MA, USA; ${ }^{6}$ University of California, Los Angeles, Los Angeles, CA, USA; ${ }^{7}$ Emory University, Atlanta, GA, USA; ${ }^{8}$ Keck School of Medicine, University of Southern California, Los Angeles, CA, USA; ${ }^{9}$ Fred Hutchinson Cancer Research Center, Seattle, WA, USA; ${ }^{10}$ University of Utah, Salt Lake City, UT, USA; ${ }^{1}$ Georgetown University, Washington, DC, USA.
\end{abstract}

BACKGROUND: Guidelines recommend against treating localized prostate cancer $(\mathrm{PCa})$ in men with a greater than10-year life expectancy. However, physicians have difficulty accurately estimating life expectancy.

OBJECTIVE: We used data from a population-based observational study to develop a nomogram to estimate long-term other-cause mortality based on self-reported health status (SRHS), race/ethnicity, and age at diagnosis.

DESIGN: This was an observational study.

SUBJECTS: Men diagnosed with localized PCa from October 1994 through October 1995 participated in the study.

MAIN MEASURES: Initial measures obtained 6 months after diagnosis included sociodemographic and tumor characteristics, treatment, and a single item on the SRHS, with response options ranging from excellent to poor. We used Surveillance, Epidemiology, and End-Results program data to determine date and cause of death through December 2010. We estimated other-cause mortality with proportional hazards survival analyses, accounting for competing risks.

KEY RESULTS: We evaluated 2,695 men, of whom $74 \%$ underwent aggressive therapy (surgery or radiotherapy). At the initial survey, $18 \%$ reported excellent $(\mathrm{E}), 36 \%$ very good (VG), $31 \% \operatorname{good}(\mathrm{G})$, and $15 \%$ fair/poor (F/P) health. Healthier men were younger, and more likely to be white, better educated, and to undergo surgery. At follow-up, $44 \%$ of the cohort had died; $78 \%$ of deaths were from causes other than PCa. SRHS predicted other-cause mortality; for men reporting $\mathrm{E}, \mathrm{VG}, \mathrm{G}, \mathrm{F} / \mathrm{P}$ health, the cumulative incidences of other-cause mortality were $20 \%$, $29 \%, 40 \%$, and $53 \%$, respectively, p<0.001. Compared to a reference of excellent SRHS, multivariable hazard ratios (95 \% CI) for other-cause mortality for men reporting $\mathrm{VG}, \mathrm{G}$, and $\mathrm{F} / \mathrm{P}$ health were 1.22 (0.97-1.54), 1.73 (1.38-2.17), and 2.71 (2.11-3.48), respectively.

Received May 29, 2014

Revised October 8, 2014

Accepted December 23, 2014

Published online February 13, 2015
CONCLUSIONS: Responses to a one-item SRHS measure were strongly associated with other-cause mortality 15 years after PCa diagnosis. Men reporting fair/poor health had substantial risks for other-cause mortality, suggesting limited benefit for undergoing aggressive treatment. SRHS can be considered in supporting informed decision-making about PCa treatment.

KEY WORDS: prostatic neoplasms; cause of death; health status.

J Gen Intern Med 30(7):924-34

DOI: $10.1007 / \mathrm{s} 11606-014-3171-8$

(C) Society of General Internal Medicine 2015

P rostate cancers detected by prostate-cancer specific antigen (PSA) testing are often indolent. ${ }^{1}$ Consequently, guidelines suggest observation (watchful waiting) for men with limited life expectancies ( $<10$ years) who are diagnosed with localized prostate cancer, because they are unlikely to realize any survival benefit from treatment. ${ }^{2,3}$ However, studies consistently show that men with limited life expectancy often receive aggressive treatment for even low-risk, localized cancers. ${ }^{4,5}$

One explanation is that physicians have difficulty accurately estimating the effect of competing mortality risks on life expectancy. ${ }^{6-8}$ Several comorbidity measures have been developed based on claims data, ${ }^{9,10}$ but these tools are most widely used in health services research. ${ }^{11}$ The American Urological Association (AUA) treatment guideline suggests using life-table analyses to inform treatment decisions, ${ }^{2}$ but these population-based estimates exclude health status and may not be readily applicable to predicting the life expectancy of an individual patient. ${ }^{12}$ Indeed, life tables have been shown to have limited predictive value for men undergoing radiation therapy ${ }^{13}$ or radical prostatectomy. ${ }^{6}$ While some multivariate predictive models, particularly those incorporating comorbidity, appear to accurately estimate life expectancy, ${ }^{14-18}$ their performance for men with prostate cancer is variable or unknown. ${ }^{19}$ Furthermore, many 
of these measures are not widely used in clinical practice. ${ }^{20}$ Welch and colleagues showed that self-reported health status could better approximate "physiologic" age as a way of estimating treatment benefits for the elderly. ${ }^{21}$ A meta-analysis has shown that a single item assessing general self-rated health can accurately predict overall mortality. ${ }^{22}$

We used self-reported health status and 15-year vital status data to estimate the risk of other-cause mortality among a population-based cohort of men with localized prostate cancer. We created a nomogram incorporating self-reported health status, age, and race/ethnicity to estimate other-cause mortality at 10 and 15 years after diagnosis.

\section{METHODS}

The Prostate Cancer Outcomes Study (PCOS) cohort was assembled using the Surveillance, Epidemiology and EndResults (SEER) program, which provides information on cancer incidence, treatment, and survival for a population-based sample of about $15 \%$ of the United States. Details of the PCOS have been published elsewhere. ${ }^{23}$ Briefly, the study used a rapid case ascertainment system to identify all men diagnosed with microscopically confirmed primary invasive adenocarcinoma of the prostate between 1 October 1994, and 31 October 1995. Patients were diagnosed in six SEER tumor registries covering the states of Connecticut, Utah, and New Mexico, and the metropolitan areas of Atlanta, Georgia; Los Angeles County, California; and King County, Washington (which includes Seattle). The Institutional Review Board of each PCOS site approved the study.

The PCOS randomly sampled a total of 5,672 subjects from the 11,137 eligible PCa cases. A pre-specified sampling strategy was employed that oversampled younger men, Hispanics, and blacks. We calculated sample weights as the inverse of the sampling proportions within each region-race-age group stratum. This permitted estimates of combined data across these strata that were appropriately weighted to the total number of eligible prostate cancer patients in the six SEER regions. ${ }^{23}$ Overall, 3,196 men (56\%) completed a sociodemographic and health-related quality-of-life survey at 6 months after initial diagnosis. For the current analysis, we evaluated the 2,695 men diagnosed with clinically localized cancer who answered the health status question on the 6-month survey.

Data Collection. At the time of initial enrollment, investigators contacted patients by mail and/or telephone and requested them to complete a self-administered survey. Demographic and socioeconomic questions were used to determine race/ethnicity, employment status, educational level, household income, insurance coverage, and marital status. Additional questions asked about comorbidity (12 medical conditions likely to affect long-term quality of life based on the Charlson comorbidity index) and disease-specific and general health-related quality of life. We asked subjects to report their health status based on the single Medical Outcomes Study Short-Form 36 item $^{24}$ : “in general would you say your health is: excellent, very good, good, fair, or poor."

We identified subjects with clinically localized prostate cancer based on an SEER algorithm using clinical information abstracted from medical records. The algorithm defined T1 tumors as confined to the prostate with a normal digital rectal examination and no positive scans (magnetic resonance imaging, computed tomography, bone scan) or evidence of metastases. T2 tumors were defined as confined to the prostate, with abnormal or suspicious digital rectal examinations, but no positive scans or evidence of metastases. We used data from the SEER Person File, medical record abstractions, and survey responses to determine treatment received by the time of the 6month survey.

We obtained vital status information from the SEER tumor registries in the spring of 2011 that provided follow-up through the end of 2010, roughly 15 years after study initiation. When a subject dies, registries obtain computerized death data files from their local departments of health and/or the National Death Index, with the underlying cause of death coded using established algorithms maintained by the National Center for Health Statistics. ${ }^{25}$

\section{Statistical Analyses}

We compared demographic and clinical variables according to health status reported on the 6-month survey. We collapsed the categories of fair/poor due to small samples sizes. We also compared overall, other-cause, and prostate-cancer specific mortality for the four health status groups. We used chisquare tests for categorical variables, weighted for the stratified sampling strategy.

We estimated overall mortality using the Kaplan-Meier method for each stratum defined by self-reported health status. We estimated cumulative incidence functions to compare the prostate cancer specific and other-cause (nonprostate cancer) mortality according to self-reported health status, while treating the other death type as a competing risk. Other-cause mortality was modeled with the proportional subdistribution hazards regression described by Fine and Gray, ${ }^{26}$ with prostate cancer death treated as competing risk. The multivariable models included age, race/ethnicity, and self-reported health status as the pre-specified covariates, and were adjusted for sampling weights, SEER registry, primary treatment, insurance, education, marital status, employment, PSA level, and Gleason score. To fit a Fine and Gray model with sampling weights, generate nomograms (graphic arrangements of multiple linear scales such that an intersecting straight line enables values predicated on the linear scales to be read from an additional scale), and assess goodness of fit, we used the connection between Fine and Gray models and weighted Cox proportional-hazard models reported by Geskus. ${ }^{27}$ We evaluated the model fit by using likelihood ratio tests to compare full and nested models. We 
Table 1. Weighted Percentage Distributions of Demographic and Clinical Characteristics at Diagnosis by Categories of Initial Self-Reported Health status

\begin{tabular}{|c|c|c|c|c|c|c|}
\hline \multirow[t]{2}{*}{ Variables } & \multirow[t]{2}{*}{ Total $(\mathrm{N}=2,695)$} & \multicolumn{4}{|c|}{ Self-reported health status } & \multirow[t]{2}{*}{ p value } \\
\hline & & $\begin{array}{l}\text { Excellent } \\
(n=481)\end{array}$ & $\begin{array}{l}\text { Very good } \\
(n=974)\end{array}$ & $\begin{array}{l}\text { Good } \\
(n=840)\end{array}$ & $\begin{array}{l}\text { Fair/Poor } \\
(n=400)\end{array}$ & \\
\hline \multicolumn{6}{|l|}{ Registry } & 0.03 \\
\hline Connecticut & 584 & $107(22 \%)$ & $230(23 \%)$ & $179(21 \%)$ & $68(17 \%)$ & \\
\hline New Mexico & 290 & $55(11 \%)$ & $84(9 \%)$ & $94(11 \%)$ & $57(14 \%)$ & \\
\hline Seattle & 169 & $32(7 \%)$ & $60(6 \%)$ & $55(7 \%)$ & $22(6 \%)$ & \\
\hline Utah & 283 & $41(9 \%)$ & $109(11 \%)$ & $101(12 \%)$ & $32(8 \%)$ & \\
\hline Atlanta & 374 & $59(12 \%)$ & $134(14 \%)$ & $105(13 \%)$ & $76(19 \%)$ & \\
\hline Los Angeles & 995 & $187(39 \%)$ & $357(37 \%)$ & $306(36 \%)$ & $145(36 \%)$ & \\
\hline \multicolumn{6}{|l|}{ Primary treatment } & $<0.001$ \\
\hline Surgery $^{\dagger}$ & 1,331 & $307(64 \%)$ & $530(54 \%)$ & $367(44 \%)$ & $127(32 \%)$ & \\
\hline Radiotherapy & 670 & $94(20 \%)$ & $237(25 \%)$ & $232(28 \%)$ & $107(26 \%)$ & \\
\hline ADT only & 260 & $25(5 \%)$ & $66(7 \%)$ & $97(11 \%)$ & $72(18 \%)$ & \\
\hline Watchful waiting & 434 & $55(11 \%)$ & $141(14 \%)$ & $144(17 \%)$ & $94(24 \%)$ & \\
\hline Age at diagnosis (median, quartiles) & $68(62,73)$ & $65(60,71)$ & $67(62,72)$ & $69(63,74)$ & $70(64,75)$ & $<0.001$ \\
\hline$<50$ & 45 & $9(2 \%)$ & $20(2 \%)$ & $14(2 \%)$ & $2(0 \%)$ & \\
\hline $50-69$ & 1,537 & $317(66 \%)$ & $587(60 \%)$ & $438(52 \%)$ & $195(49 \%)$ & \\
\hline $70+$ & 1,113 & $155(32 \%)$ & $367(38 \%)$ & $388(46 \%)$ & $203(51 \%)$ & \\
\hline \multicolumn{6}{|l|}{ Race } & $<0.001$ \\
\hline White & 2,070 & $386(80 \%)$ & $787(81 \%)$ & $631(75 \%)$ & $266(67 \%)$ & \\
\hline Black & 348 & $54(11 \%)$ & $104(11 \%)$ & $122(15 \%)$ & $69(17 \%)$ & \\
\hline Hispanic & 277 & $41(9 \%)$ & $83(8 \%)$ & $87(10 \%)$ & $65(16 \%)$ & \\
\hline \multicolumn{6}{|l|}{ Insurance } & $<0.001$ \\
\hline Medicare & 1,254 & $186(39 \%)$ & $442(45 \%)$ & $402(48 \%)$ & $224(56 \%)$ & \\
\hline Private/military & 1,194 & $247(51 \%)$ & $457(47 \%)$ & $346(41 \%)$ & $144(36 \%)$ & \\
\hline Medicaid/other/none & 47 & $7(1 \%)$ & $9(1 \%)$ & $23(3 \%)$ & $8(2 \%)$ & \\
\hline Unknown & 200 & $41(9 \%)$ & $66(7 \%)$ & $69(8 \%)$ & $24(6 \%)$ & \\
\hline \multicolumn{6}{|l|}{ Education } & $<0.001$ \\
\hline$<$ High school (HS) & 539 & $52(11 \%)$ & $151(16 \%)$ & $197(24 \%)$ & $139(34 \%)$ & \\
\hline HS/some college & 1,173 & $175(36 \%)$ & $437(45 \%)$ & $385(46 \%)$ & $176(44 \%)$ & \\
\hline College & 406 & $99(21 \%)$ & $168(17 \%)$ & $112(13 \%)$ & $27(7 \%)$ & \\
\hline Advanced degree & 544 & $149(31 \%)$ & $209(21 \%)$ & $135(16 \%)$ & $51(13 \%)$ & \\
\hline Unknown/refused & 33 & $6(1 \%)$ & $9(1 \%)$ & $11(1 \%)$ & $7(2 \%)$ & \\
\hline \multicolumn{6}{|l|}{ Marital status } & 0.16 \\
\hline Married/partnered & 2,150 & $396(82 \%)$ & $795(81 \%)$ & $662(79 \%)$ & $297(74 \%)$ & \\
\hline Single & 522 & $81(17 \%)$ & $172(18 \%)$ & $170(20 \%)$ & $99(25 \%)$ & \\
\hline Unknown/refused & 23 & $4(1 \%)$ & $7(1 \%)$ & $8(1 \%)$ & $4(1 \%)$ & \\
\hline \multicolumn{6}{|l|}{ Employment } & $<0.001$ \\
\hline Working full-time & 617 & $176(37 \%)$ & $251(26 \%)$ & $162(19 \%)$ & $28(7 \%)$ & \\
\hline Working part-time & 260 & $37(8 \%)$ & $107(10 \%)$ & $82(10 \%)$ & $34(9 \%)$ & \\
\hline Retired & 1,701 & $256(53 \%)$ & $583(60 \%)$ & $564(67 \%)$ & $298(75 \%)$ & \\
\hline Other/refused & 117 & $12(2 \%)$ & $33(4 \%)$ & $32(4 \%)$ & $40(10 \%)$ & \\
\hline PSA level (median, quartiles) & $7.3(5.3,10.9)$ & $7.3(5.3,10.9)$ & $7.7(5.5,12.9)$ & $7.7(5.4,13.5)$ & $9.6(5.6,17.1)$ & $<0.001$ \\
\hline$<4 \mathrm{ng} / \mathrm{mL}$ & 252 & $44(9 \%)$ & $79(8 \%)$ & $78(9 \%)$ & $51(13 \%)$ & \\
\hline $4-10 \mathrm{ng} / \mathrm{mL}$ & 1,381 & $284(59 \%)$ & $520(53 \%)$ & $429(51 \%)$ & $148(37 \%)$ & \\
\hline$>10 \mathrm{ng} / \mathrm{mL}$ & 900 & $132(27 \%)$ & $318(33 \%)$ & $278(33 \%)$ & $172(43 \%)$ & \\
\hline Unknown & 162 & $21(4 \%)$ & $57(6 \%)$ & $55(7 \%)$ & $29(7 \%)$ & \\
\hline \multicolumn{6}{|l|}{ Gleason score } & $<0.001$ \\
\hline$\leq 6$ & 1,189 & $258(54 \%)$ & $442(45 \%)$ & $349(42 \%)$ & $140(35 \%)$ & \\
\hline$\overline{7}-10$ & 627 & $95(19 \%)$ & $203(21 \%)$ & $205(24 \%)$ & $124(31 \%)$ & \\
\hline Unknown & 879 & $128(27 \%)$ & $329(34 \%)$ & $286(34 \%)$ & $136(34 \%)$ & \\
\hline \multicolumn{6}{|l|}{ Comorbidity } & $<0.001$ \\
\hline 0 & 1,006 & $276(58 \%)$ & $443(45 \%)$ & $226(27 \%)$ & $61(15 \%)$ & \\
\hline 1 & 880 & $150(31 \%)$ & $353(36 \%)$ & $285(34 \%)$ & $92(23 \%)$ & \\
\hline 2 & 440 & $45(9 \%)$ & $129(13 \%)$ & $178(21 \%)$ & $88(22 \%)$ & \\
\hline $3+$ & 369 & $10(2 \%)$ & $49(5 \%)$ & $151(18 \%)$ & $159(40 \%)$ & \\
\hline
\end{tabular}

Weighted for oversampling younger, Hispanic, and black men PSA prostate-specific antigen

${ }^{+}$Could also receive radiotherapy and/or androgen deprivation

${ }^{*}$ Could also receive androgen deprivation

used the method of Gonen and Heller, which estimates the concordance index, to assess the discriminatory power of the multivariable model. ${ }^{28}$ The concordance index has the same interpretation as Harrell's $\mathrm{C}$ statistic for survival data. ${ }^{29} \mathrm{We}$ used a two-sided $p$ value of 0.05 to denote statistical significance. Statistical analyses were performed by R 3.0 with survey, mstate, rms, clinfun, and pec packages. ${ }^{30-36}$

\section{RESULTS}

Demographic and clinical characteristics from the initial survey, stratified by self-reported health status and weighted for the stratified sampling strategy, are shown in Table 1. Overall, $18 \%$ of men rated themselves as being in excellent health, $36 \%$ as very good health, $31 \%$ as good health, and $15 \%$ as 
fair/poor health. Compared to men reporting excellent health, those reporting only good or fair/poor health status at the time of diagnosis were more likely to be older, be of minority race, and have more comorbidities. The men reporting poorer health status were also less likely to have an advanced degree, be working fulltime, have private insurance, or undergo aggressive treatment.

When subjects were surveyed, 2,001 (74\%) had already attempted curative therapy with either surgery or radiotherapy. Compared to men who received either ADT or watchful waiting, men attempting curative therapy were younger, healthier, had higher socioeconomic status, lower PSA and Gleason scores, and higher self-reported health status and lower comorbidity scores (Appendix Table 4). Men undergoing surgery or radiotherapy also had significantly lower mortality, particularly from causes other than prostate cancer.

Figures 1, 2 and 3 are Kaplan-Meier curves showing the cumulative incidences of overall, other-cause, and prostatecancer specific mortality stratified by self-reported health status. Self-reported health status was significantly associated with overall $(p<0.001)$ and other-cause $(p<0.001)$ mortality. Men reporting excellent health were significantly less likely than those reporting fair/poor health to die during follow-up $(p<0.001)$ or to die from other causes $(p<0.001)$. However, prostate cancer mortality was similar across health status strata. We observed the same results for men who had not undergone surgery or radiotherapy at the time of reporting health status (Appendix Fig. 5).

The weighted probabilities for overall, other-cause, and prostate-cancer specific mortality are shown in Table 2. By 15 years after diagnosis, $44 \%$ of the cohort had died; $78 \%$ of the deaths were due to causes other than prostate cancer. The proportions of subjects with overall and other-cause deaths increased with worsening self-reported health status. Overall mortality was $27 \%$ among men reporting excellent health, with $74 \%$ of the deaths from causes other than prostate cancer. However, among men reporting fair/poor health status, overall

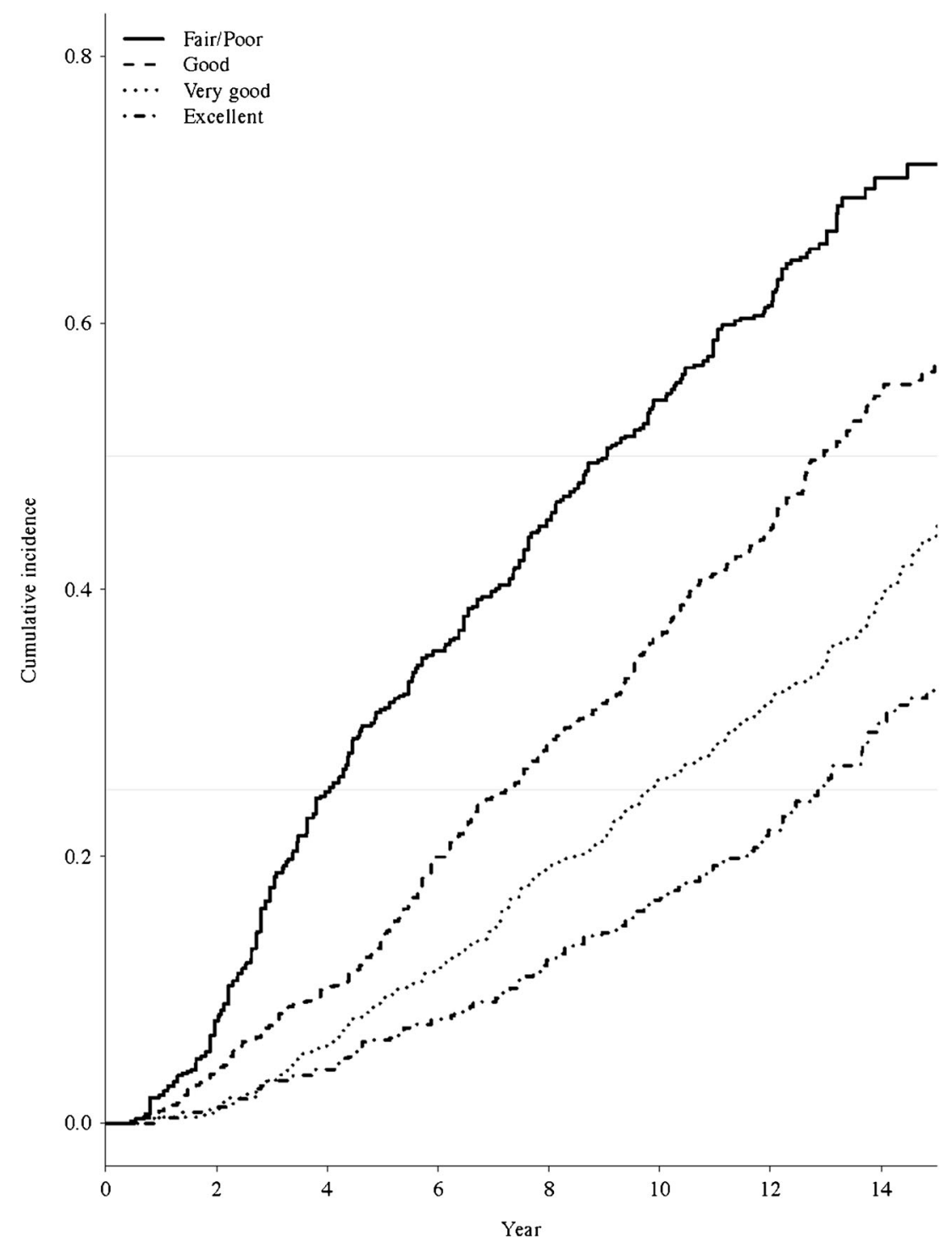

Figure 1. Competing risks cumulative incidence curve for overall mortality by initial self-reported health status. 


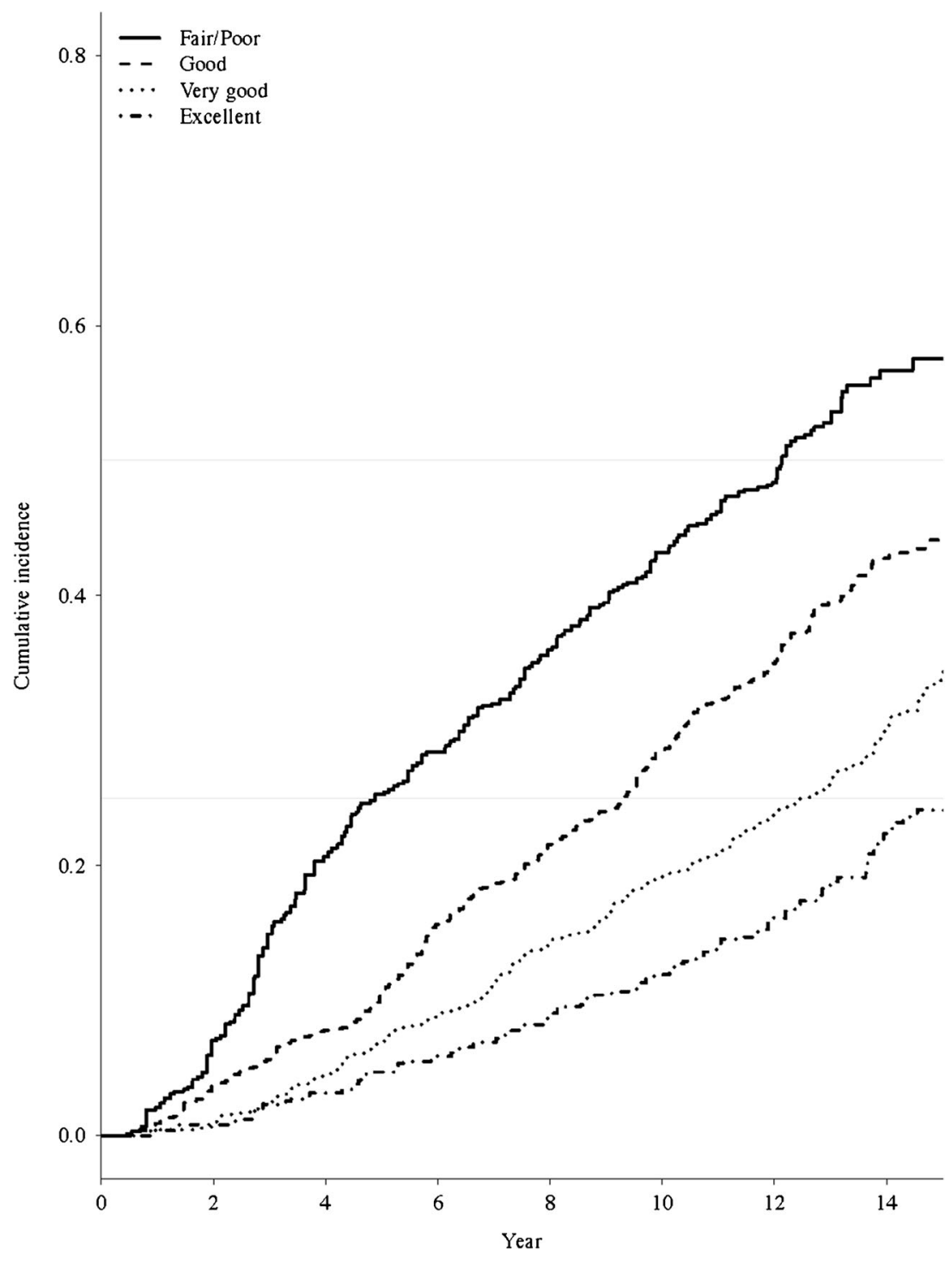

Figure 2. Competing risks cumulative incidence curve for other-cause mortality by initial self-reported health status.

mortality was $66 \%$, and $81 \%$ of the deaths were from causes other than prostate cancer.

Results from the multivariable competing risks model for other-cause (non-prostate cancer) death are shown in Table 3. The likelihood ratio statistic for this model $=764$ (degrees of freedom $=30$ ), $p<0.0001$. Self-reported health status is significantly associated with other-cause death in this treatmentadjusted model. We also ran the model without adjusting for treatment and the hazards ratios for self-reported health status were essentially identical. Compared to a reference group of excellent health, the hazard ratios for other-cause death for men reporting very good, good, and fair/poor health were 1.22 (95 \% CI 0.97, 1.54), $1.78(1.42,2.23)$, and $2.87(2.24,3.68)$, respectively.

We also ran the model substituting comorbidity counts for self-reported health status; the associated hazards ratios were similar to those for self-reported health status. However, selfreporting fair/poor health was associated with a greater risk for other-cause death $(\mathrm{HR}=2.71,95 \%$ CI $2.11,3.48)$ than the highest comorbidity score $(\mathrm{HR}=2.06,95 \% \mathrm{CI} 1.68,2.51)$. The likelihood ratio (LR) tests for comparing models showed similar effects for adding to the simpler model either comorbidity $(L R=85, p<0.0001)$ or self-reported health status ( $L R=58, p<0.0001)$. The multivariable model with age, race/ ethnicity and self-reported health status yielded a concordance index of 0.73 (95\% CI 0.72-0.74).

The nomogram (Fig. 4) can be used to estimate the 10year and 15-year probabilities for other-cause death for men with localized prostate cancer according to age at diagnosis, race and ethnicity, and self-reported health status. Increasing age and poorer self-reported health status were associated with increased risk for other-cause death. For example, a 69-year-old black man reporting fair/poor health status had just over a $30 \%$ chance of other-cause death after 10 years and a greater than $50 \%$ chance of other-cause death after 15 years. Meanwhile, the corresponding risks for a 69 -year-old white man reporting excellent health were about 15 and $25 \%$, respectively. 


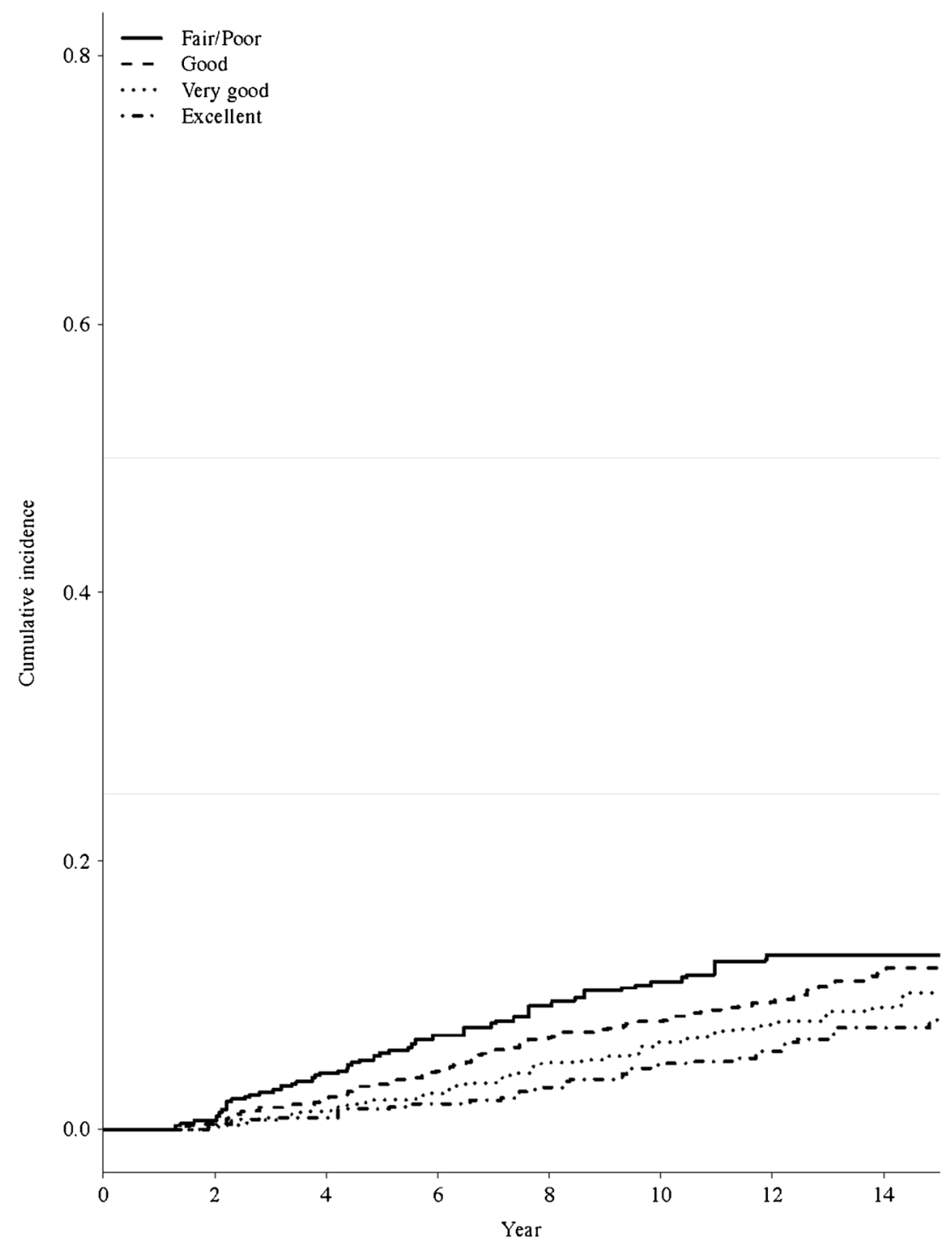

Figure 3. Competing risks cumulative incidence curve for prostate-cancer-specific mortality by initial self-reported health status.

\section{DISCUSSION}

We found a substantial 15-year overall mortality risk, mostly arising from non-cancer causes, among a population-based cohort of men with localized prostate cancer. Just over one-third of the men reported excellent health, while $15 \%$ reported fair/poor health. The initial self-reported health status significantly correlated with overall and non-cancer mortality, with marked differences between men self-reporting excellent vs. fair/poor health. Self-reported health status was independently associated with non-cancer mortality and performed similarly to modeling with comorbidity counts. We developed a nomogram to predict 10 -year and 15 -year risks for othercause deaths based on age at diagnosis, race and ethnicity, and self-reported health status.

Table 2. 15-year Mortality and Survival by Categories of Initial Self-Reported Health Status

\begin{tabular}{|c|c|c|c|c|c|c|}
\hline \multirow[t]{2}{*}{ Outcome } & \multirow[t]{2}{*}{ Number of events $(\mathrm{N}=\mathbf{2 , 6 9 5 )}$} & \multicolumn{4}{|c|}{ Self-reported health status } & \multirow[t]{2}{*}{ p value } \\
\hline & & Excellent $(n=481)$ & $\begin{array}{l}\text { Very Good } \\
(\mathrm{n}=974)\end{array}$ & $\begin{array}{l}\text { Good } \\
(n=840)\end{array}$ & $\begin{array}{l}\text { Fair/Poor } \\
(n=400)\end{array}$ & \\
\hline $\begin{array}{l}\text { Overall mortality } \\
\text { Prostate cancer death } \\
\text { Other-cause death } \\
\text { Alive }\end{array}$ & $\begin{array}{l}1,190(44 \%) \\
263(10 \%) \\
927(34 \%) \\
1,505(56 \%)\end{array}$ & $\begin{array}{l}130(27 \%) \\
34(7 \%) \\
96(20 \%) \\
351(77 \%)\end{array}$ & $\begin{array}{l}365(37 \%) \\
86(9 \%) \\
279(29 \%) \\
609(63 \%)\end{array}$ & $\begin{array}{l}432(51 \%) \\
92(11 \%) \\
340(40 \%) \\
408(49 \%)\end{array}$ & $\begin{array}{l}263(66 \%) \\
51(13 \%) \\
212(53 \%) \\
137(34 \%)\end{array}$ & $<0.001$ \\
\hline
\end{tabular}

Weighted for oversampling younger, Hispanic, and black men 
Table 3. Multivariate Proportional Hazards Model for Predicting Other-Cause Deaths

\begin{tabular}{|c|c|}
\hline Variables & Hazard Ratios (95 \% CI) \\
\hline \multicolumn{2}{|l|}{ Self reported health status } \\
\hline Excellent & Reference \\
\hline Very good & $1.22(0.97-1.54)$ \\
\hline Good & $1.73(1.38-2.17)$ \\
\hline Fair/Poor & $2.71(2.11-3.48)$ \\
\hline \multicolumn{2}{|l|}{ Registry } \\
\hline Connecticut & Reference \\
\hline New Mexico & $1.48(1.17-1.85)$ \\
\hline Seattle & $1.33(1.04-1.71)$ \\
\hline Utah & $1.19(0.84-1.67)$ \\
\hline Atlanta & $1.59(1.28-1.98)$ \\
\hline Los Angeles & $1.34(1.09-1.64)$ \\
\hline \multicolumn{2}{|l|}{ Primary Treatment } \\
\hline Surgery ( \pm radiotherapy, ADT) & Reference \\
\hline Radiotherapy $( \pm \mathrm{ADT})$ & $1.17(0.98-1.40)$ \\
\hline ADT only & $1.33(1.04-1.70)$ \\
\hline Watchful waiting & $1.37(1.10-1.71)$ \\
\hline Age at diagnosis 60 to 72 years $^{\dagger}$ & $2.59(2.19-3.06)$ \\
\hline \multicolumn{2}{|l|}{ Race } \\
\hline White & Reference \\
\hline Black & $1.05(0.84-1.31)$ \\
\hline Hispanic & $0.69(0.52-0.91)$ \\
\hline \multicolumn{2}{|l|}{ Insurance } \\
\hline Medicare & Reference \\
\hline Private/military & $0.93(0.78-1.11)$ \\
\hline Medicaid/other/none & $1.15(0.88-1.51)$ \\
\hline \multicolumn{2}{|l|}{ Education } \\
\hline$<$ High school (HS) & Reference \\
\hline HS/some college & $1.11(0.93-1.32)$ \\
\hline College & $0.71(0.55-0.90)$ \\
\hline Advanced degree & $0.53(0.42-0.68)$ \\
\hline \multicolumn{2}{|l|}{ Marital status } \\
\hline Married/partnered & Reference \\
\hline Single & $1.25(1.06-1.47)$ \\
\hline \multicolumn{2}{|l|}{ Employment } \\
\hline Working full-time & Reference \\
\hline Working part-time & $0.84(0.61-1.16)$ \\
\hline Retired & $1.25(0.99-1.59)$ \\
\hline Other & $0.78(0.46-1.30)$ \\
\hline $\mathrm{PSA}^{\dagger} 5.4$ to 13.2 & $0.99(0.93,1.05)$ \\
\hline \multicolumn{2}{|l|}{ Gleason score } \\
\hline$\leq 6$ & Reference \\
\hline 7 & $1.26(1.08-1.47)$ \\
\hline $8-10$ & $1.23(0.99-1.51)$ \\
\hline
\end{tabular}

${ }^{\dagger}$ Modeled as continuous variable, values refer to lower and upper quartiles; hazard ratios represent comparison of upper vs. lower quartile

Weighted for oversampling younger, Hispanic, and black men ADT androgen deprivation therapy

Prostate cancers are often indolent, and men with prostate cancer who are older or in poor health face much greater mortality risks from competing causes of death. These men are unlikely to realize a prostate-cancer survival benefit with aggressive treatment. ${ }^{37,38}$ Consequently, treatment recommendations are predicated on whether the patient can be expected to have a 10 -year to 15 -year life expectancy. ${ }^{2,3}$

Although competing risks of mortality for men with localized prostate cancer are well recognized, ${ }^{38,39}$ clinicians often poorly estimate life expectancy. ${ }^{6,7}$ Adjusting life tables for comorbidity scores obtained from the SEER-Medicare database improves non-cancer survival estimates for recently diagnosed cancer patients. ${ }^{16}$ Comorbidity-adjusted life expectancy varied considerably among Medicare beneficiaries, suggesting the importance of considering comorbidity in tailoring treatment decisions in older patients. ${ }^{15}$ While life table and comorbidity counts can accurately estimate life expectancy, these measures have not been widely used in clinical practice for men with prostate cancer. ${ }^{20}$ There are now online estimators, such as eprognosis (http://eprognosis.ucsf.edu) that can more readily support decision-making by enabling providers or patients to populate a risk calculator using validated prognostic indices derived from community-dwelling older adults. Risk scores are based on $11^{18}$ and $12^{17}$ multidimensional predictors, respectively. Our nomogram, derived from a population of men with localized prostate cancer, is based just on age, race/ethnicity, and a single question self-report health status measure. The nomogram could be a simpler way to engage patients in decision-making for prostate cancer treatment. However, an online application would likely be necessary for facilitating uptake, particularly in a clinic setting.

The nomogram is based on patient characteristics from a cohort assembled in the mid-1990s and cannot precisely estimate risks for men currently diagnosed with localized prostate cancer. We also did not validate the nomogram in other populations. However, we are unaware of any other large, population-based studies that measured self-reported health status and had sufficiently long follow-up to ascertain mortality. The nomogram should eventually be evaluated in more recently assembled cohorts collecting health status data, such as the Comparative Effectiveness of Surgery and Radiation in localized prostate cancer (CEASAR) study. ${ }^{40}$

Nevertheless, the nomogram can provide men with a gist understanding of their risk for non-cancer death. ${ }^{41}$ Older men with localized prostate cancer who self-report fair or poor health have substantial risks for other-cause deaths and are unlikely to survive long enough to benefit from aggressive treatment. These men should strongly consider watchful waiting. Prostate cancer treatment decisions for men reporting intermediate levels of health, though, have become more complicated due to increasing recognition of overdiagnosis and overtreatment. ${ }^{42}$ The choices are no longer just immediate active treatment vs. watchful waiting. Active surveillance, a strategy of closely monitoring low-risk cancers with PSA testing, digital rectal examination, and serial prostate biopsies, has emerged as a viable option that allows men the opportunity to avoid active treatment in the absence of cancer progression. ${ }^{43}$ Men whose cancer progresses while on active surveillance will again face treatment decisions, which can be influenced by changes in health status - that could be captured by self-report.

Our study has some other potential limitations. The majority of men in PCOS underwent radical prostatectomy, which has been shown to reduce prostate cancer mortality in men with higher-risk cancers. ${ }^{37,44}$ Treatment recommendations have changed over the past few decades, and more men with localized prostate cancers are being encouraged to consider observation. $^{2}$ This could mean higher prostate-cancer mortality rates, though that would differentially impact men reporting excellent health rather than poor health, because the latter would not 
Points

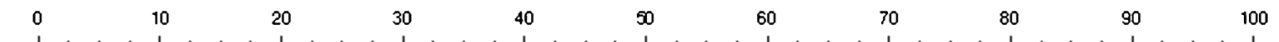

Race

Age

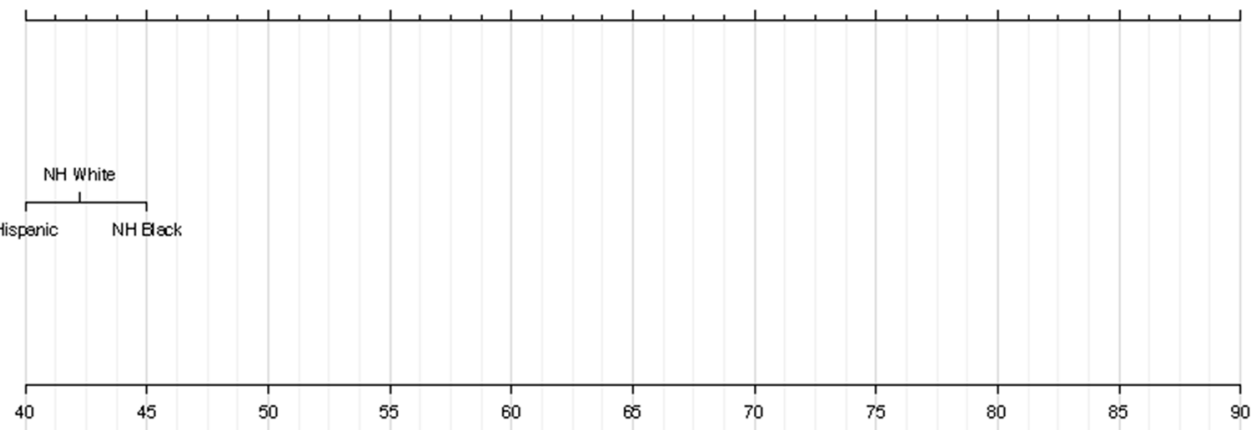

Self-reported Health Status

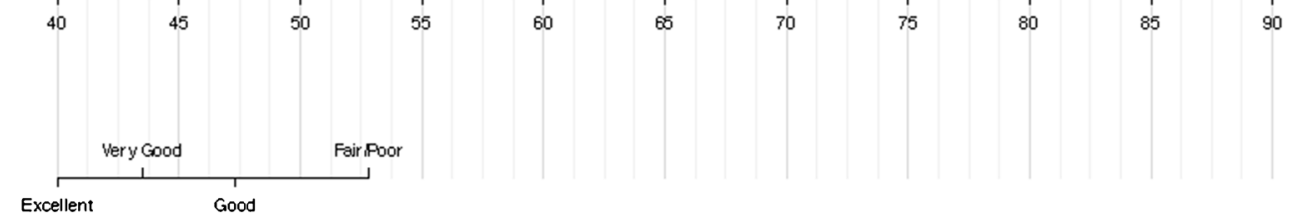

Total Points

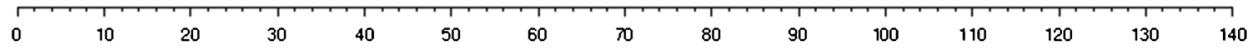

10 years Other cause death probability

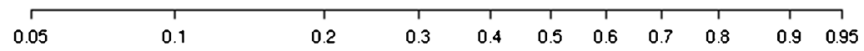

15 years Other cause death probability

\begin{tabular}{lllllllllll}
\hline 0.05 & 0.1 & 1 & 1 & 1 & 1 & 1 & \\
& & 0.2 & 0.3 & 0.4 & 0.5 & 0.6 & 0.7 & 0.8 & 0.9 & 0.95
\end{tabular}

Figure 4. Nomogram for estimating 10-year and 15-year risk of other-cause mortality. Select the appropriate age, race/ethnicity, and self-reported health status and draw a straight line for each to the points' line. The sum of the points from age, race/ethnicity, and self-reported health status equals the total points. Drawing a straight line down from total points will indicate the 10-year and 15-year risks for other-cause death.

likely be offered surgery. Misclassifying cause of death could affect mortality estimates, but death certificate data for prostate cancer deaths have been shown to be accurate, ${ }^{45}$ and the proportion of prostate cancer deaths was quite small.

Additionally, subjects completed the initial survey 6 months after diagnosis. The majority of subjects had already undergone treatment-which could lead to misclassifying self-reported initial health status, because treatment could have adversely affected quality of life, particularly for those undergoing surgery. However, we showed that men who underwent surgery or radiotherapy appeared significantly healthier at the time of being surveyed-based on both self-report and number of comorbidities - than men who had not been treated. Furthermore, the men who received surgery or radiotherapy were far less likely to die during follow-up, particularly from causes other than prostate cancer. When we modeled the association between self-reported health status and risk for other-cause death for the entire cohort, the hazard ratios were essentially identical with or without adjusting for treatment. We also showed that selfreported health status was significantly associated with death from causes other than prostate cancer in the subset of men who had not undergone surgery or radiotherapy. These findings all suggest that important misclassification, which would actually bias our results towards the null, was unlikely.

\section{CONCLUSIONS}

A substantial proportion of the population-based cohort of men diagnosed with localized prostate cancer in the mid 1990s died within 15 years of diagnosis; however, less than one-quarter of the deaths were due to prostate cancer. Men reporting fair/poor health were significantly more likely to die from causes other than prostate cancer, and were unlikely to survive long enough to benefit from aggressive treatment. A nomogram, based on just age, race/ethnicity, and the response to a single healthstatus question, can effectively stratify men with localized cancer for their risk of other-cause death at 10 and 15 years following diagnosis. This information could be used to support clinical decision-making for treating prostate cancer.

Acknowledgements: The authors thank the men who participated in PCOS for making a vital contribution to better understanding of the effects of prostate cancer on men's lives; the physicians in the 6 SEER areas who assisted in collecting data from their patients and from medical records; all of the study managers and chart abstractors for their outstanding efforts in data collection; and all of the staff in the 6 SEER cancer registries for their help with the study. 
Funding for this research was provided by the National Cancer Institute, National Institutes of Health, Bethesda, $M D$, through grant \#R01-CA114524 and the following contracts from the each of the participating institutions: NO1-PC-67007, NO1-PC-67009, NO1-PC67010, N01-PC-67006, N01-PC-67005, and N01-PC-67000.

This work was presented, in part, at the 37th Annual Meeting of the Society of General Internal Medicine, 24 April 2014, San Diego California.

Conflict of Interest: Richard M. Hoffman reports receiving salary support as a medical editor of a prostate cancer treatment decision aid for the Informed Medical Decisions Foundation, a nonprofit; and royalties from UpToDate for writing the prostate cancer-screening chapter. Michael J. Barry reports receiving salary and grant support as President and a Board Member of the Informed Medical Decisions Foundation, a nonprofit. As of 1 April 2014, the Foundation merged with Healthwise, another nonprofit, and he continues to receive salary and grant support as Chief Science Officer of Healthwise. None of the other authors reported any potential conflicts of interest.

Corresponding Author: Richard M. Hoffman, MD, MPH; University of New Mexico School of Medicine, Albuquerque, NM 87131, USA (e-mail: rhoffman@unm.edu).

\section{REFERENCES}

1. Esserman L, Shieh Y, Thompson I. Rethinking screening for breast cancer and prostate cancer. JAMA. 2009;302(15):1685-92. doi:10.1001/ jama.2009.1498.

2. Thompson I, Thrasher JB, Aus G, Burnett AL, Canby-Hagino ED, Cookson MS, et al. Guideline for the management of clinically localized prostate cancer: 2007 update. J Urol. 2007;177(6):2106-31. doi:10.1016/ j.juro.2007.03.003.

3. Mohler JL. The 2010 NCCN clinical practice guidelines in oncology on prostate cancer. J Ntnl Compr Cancer Netw: JNCCN. 2010;8(2):145

4. Shao Y-H, Albertsen PC, Roberts CB, Lin Y, Mehta AR, Stein MN, et al. Risk profiles and treatment patterns among men diagnosed with prostate cancer and a prostate specific antigen level below $4.0 \mathrm{ng} / \mathrm{ml}$. Arch Intern Med. 2010 .

5. Cooperberg MR, Broering JM, Latini DM, Litwin MS, Wallace KL, Carroll PR. Patterns of practice in the United States: insights from CaPSURE on prostate cancer management. Curr Urol Rep. 2004;5(3):166-72.

6. Walz J, Gallina A, Perrotte P, Jeldres C, Trinh QD, Hutterer GC, et al. Clinicians are poor raters of life-expectancy before radical prostatectomy or definitive radiotherapy for localized prostate cancer. BJU Int. 2007;100(6): 1254-8. doi:10.1111/j. 1464-410X.2007.07130.x.

7. Leung KM, Hopman WM, Kawakami J. Challenging the 10-year rule: The accuracy of patient life expectancy predictions by physicians in relation to prostate cancer management. Can Urol Assoc J J Assoc Urol Can. 2012;6(5):367-73. doi:10.5489/cuaj.11161.

8. Daskivich TJ, Chamie K, Kwan L, Labo J, Palvolgyi R, Dash A, et al. Overtreatment of men with low-risk prostate cancer and significant comorbidity. Cancer. 2011;117(10):2058-66. doi:10.1002/cncr.25751.

9. Charlson ME, Pompei P, Ales KL, Mackenzie CR. A new method of classifying prognostic comorbidity in longitudinal studies: development and validation. J Chron Dis. 1987;40(5):373-83.

10. Elixhauser A, Steiner C, Harris DR, Coffey RM. Comorbidity measures for use with administrative data. Med Care. 1998;36(1):8-27.

11. Sharabiani MT, Aylin P, Bottle A. Systematic review of comorbidity indices for administrative data. Med Care. 2012;50(12):1109-18. doi:10. 1097/MLR.0b013e31825f64d0.

12. Walter LC, Covinsky KE. Cancer screening in elderly patients: a framework for individualized decision making. JAMA. 2001;285(21):2750-6.

13. Walz J, Gallina A, Hutterer G, Perrotte P, Shariat SF, Graefen M, et al. Accuracy of life tables in predicting overall survival in candidates for radiotherapy for prostate cancer. Int $\mathrm{J}$ Radiat Oncol Biol Phys. 2007;69(1):88-94. doi:10.1016/j.ijrobp.2007.02.022.

14. Walz J, Gallina A, Saad F, Montorsi F, Perrotte P, Shariat SF, et al. A nomogram predicting 10-year life expectancy in candidates for radical prostatectomy or radiotherapy for prostate cancer. J Clin Oncol: Off J Am Soc Clin Oncol. 2007;25(24):3576-3581. doi:10.1200/JCO.2006.10.3820.
15. Cho H, Klabunde CN, Yabroff KR, Wang Z, Meekins A, LansdorpVogelaar I, et al. Comorbidity-adjusted life expectancy: a new tool to inform recommendations for optimal screening strategies. Ann Intern Med. 2013;159(10):667-76. doi:10.7326/0003-4819-159-10-201311190-00005.

16. Mariotto AB, Wang Z, Klabunde CN, Cho H, Das B, Feuer EJ. Life tables adjusted for comorbidity more accurately estimate noncancer survival for recently diagnosed cancer patients. J Clin Epidemiol. 2013;66(12):137685. doi:10.1016/j.jclinepi.2013.07.002.

17. Lee SJ, Lindquist K, Segal MR, Covinsky KE. Development and validation of a prognostic index for 4-year mortality in older adults. JAMA. 2006;295(7):801-8. doi:10.1001/jama.295.7.801.

18. Schonberg MA, Davis RB, McCarthy EP, Marcantonio ER. External validation of an index to predict up to 9-year mortality of communitydwelling adults aged 65 and older. J Am Geriatr Soc. 2011;59(8):1444-51. doi:10.1111/j.1532-5415.2011.03523.x.

19. Jeldres C, Latouff JB, Saad F. Predicting life expectancy in prostate cancer patients. Curr Opin Support Palliat Care. 2009;3(3):166-9. doi:10. 1097/SPC.0b013e32832e9c80.

20. Jeldres C. Life expectancy estimation in prostate cancer patients. Can Urol Assoc J. 2012;6(5):374-5.

21. Welch HG, Albertsen PC, Nease RF, Bubolz TA, Wasson JH. Estimating treatment benefits for the elderly: the effect of competing risks. Ann Intern Med. 1996;124(6):577-84.

22. DeSalvo KB, Bloser N, Reynolds K, He J, Muntner P. Mortality prediction with a single general self-rated health question. A meta-analysis. J Gen Intern Med. 2006;21(3):267-75. doi:10.1111/j.1525-1497.2005.00291.x.

23. Potosky AL, Harlan LC, Stanford JL, Gilliland FD, Hamilton AS, Albertsen PC, et al. Prostate cancer practice patterns and quality of life: the Prostate Cancer Outcomes Study. J Natl Cancer Inst. 1999;91(20): 1719-24.

24. Ware JE Jr, Sherbourne CD. The MOS 36-item short-form health survey (SF-36). I. Conceptual framework and item selection. Med Care. 1992;30(6):473-83.

25. Office of Health Statistics. Instruction manual. Part 2c, ICD-9 ACME decision tables for classifying underlying causes of death. Hyattsville In: Statistics NCfH, editor. Hyattsville, MD: US Department of Health and Human Services, Public Health Service; 1981.

26. Fine JP, Gray RJ. A proportional hazards model for the sub-distribution of a competing risk. J Am Stat Assoc. 1999;94:496-509.

27. Geskus RB. Cause-specific cumulative incidence estimation and the fine and gray model under both left truncation and right censoring. Biometrics. 2011;67(1):39-49. doi:10.1111/j.1541-0420.2010.01420.x.

28. Gonen M, Heller G. Concordance probability and discriminatory power in proportional hazards regression. Biometrika. 2005;92:965-970.

29. Harrell FE Jr, Lee KL, Califf RM, Pryor DB, Rosati RA. Regression modelling strategies for improved prognostic prediction. Stat Med. 1984;3(2): 143-52.

30. R Development Core Team. A language and enviroment for statistical computing. Vienna: R Foundation for Statistical Computing; 2011.

31. Lumley T. Analysis of complex survey samples. J Stat Softw. 2004;9(1):1-19.

32. de Wreede LC, Fiocco M, Putter H. mstate: An R Package for the Analysis of Competing Risks and Multi-State Models. J Stat Softw. 2009;38(7): 1-30.

33. Putter H, Fiocco M, Geskus RB. Tutorial in biostatistics: competing risks and multi-state models. Stat Med. 2007;26(11):2389-430. doi:10.1002/ $\operatorname{sim} .2712$.

34. Harrell FE. rms: Regression Modeling Strategies. 2012.

35. Seshan VE. Clinical Trial Design and Data Analysis Function. 1.0.6 ed: R Foundation for Statistical Computing; 2014.

36. Mogensen UB, Ishwaran H, Gerds TA. Evaluating random forests for survival analysis using prediction error curves. J Stat Softw. 2012;50(11, September).

37. Bill-Axelson A, Holmberg L, Ruutu M, Garmo H, Stark JR, Busch C, et al. Radical prostatectomy versus watchful waiting in early prostate cancer. N Engl J Med. 2011;364(18):1708-17. doi:10.1056/NEJMoa1011967.

38. Daskivich TJ, Fan KH, Koyama T, Albertsen PC, Goodman M, Hamilton AS, et al. Effect of age, tumor risk, and comorbidity on competing risks for survival in a U.S. population-based cohort of men with prostate cancer. Ann Intern Med. 2013;158(10):709-17. doi:10.7326/ 0003-4819-158-10-201305210-00005.

39. Albertsen PC, Fryback DG, Storer BE, Kolon TF, Fine J. The impact of co-morbidity on life expectancy among men with localized prostate cancer. J Urol. 1996; 156(1): 127-32.

40. Barocas DA, Chen V, Cooperberg M, Goodman M, Graff JJ, Greenfield $\mathbf{S}$, et al. Using a population-based observational cohort study to address difficult comparative effectiveness research questions: the CEASAR study. J Comp Eff Res. 2013;2(4):445-60. doi:10.2217/cer.13.34. 
41. Brust-Renck PG, Royer CE, Reyna VF. Communicating Numerical Risk: Human Factors That Aid Understanding in Health Care. Rev Hum Factors Ergono. 2013;8(1):235-76. doi:10.1177/1557234X13492980.

42. Chou R, Croswell JM, Dana T, Bougatsos C, Blazina I, Fu R, et al. Screening for prostate cancer: a review of the evidence for the U.S. Preventive Services Task Force. Ann Intern Med. 2011;155(11):762-71. doi:10.7326/0003-4819-155-11-201112060-00375.

43. Ganz PA, Barry JM, Burke W, Col NF, Corso PS, Dodson E, et al. National Institutes of Health State-of-the-Science Conference: role of active surveillance in the management of men with localized prostate cancer. Ann Intern Med. 2012;156(8):591-5. doi:10.7326/0003-4819-156-8201204170-00401.

44. Wilt TJ, Brawer MK, Jones KM, Barry MJ, Aronson WJ, Fox S, et al Radical prostatectomy versus observation for localized prostate cancer. N Engl J Med. 2012;367(3):203-13. doi:10.1056/NEJMoa1113162.

45. Penson DF, Albertsen PC, Nelson PS, Barry M, Stanford JL. Determining cause of death in prostate cancer: are death certificates valid? J Natl Cancer Inst. 2001;93(23): 1822-3.

\section{APPENDIX}

Table 4. Comparison of Subjects Reporting Active Treatment vs. Conservative Management on the 6-Month Survey

\begin{tabular}{|c|c|c|c|c|}
\hline Variable & Number (Total $\mathrm{N}=\mathbf{2 , 6 9 5})$ & Surgery or radiotherapy $n=2001$ & ADT/WW n=694 & p value \\
\hline Registry & & & & $<0.001$ \\
\hline Connecticut & 584 & $450(23 \%)$ & $134(19 \%)$ & \\
\hline New Mexico & 290 & $188(9 \%)$ & $102(15 \%)$ & \\
\hline Seattle & 169 & $115(6 \%)$ & $53(8 \%)$ & \\
\hline Utah & 283 & $216(11 \%)$ & $67(10 \%)$ & \\
\hline Atlanta & 374 & $326(16 \%)$ & $48(7 \%)$ & \\
\hline Los Angeles & 995 & $706(35 \%)$ & $290(41 \%)$ & \\
\hline Self Reported Health Status & & & & $<0.001$ \\
\hline Excellent & 481 & $401(20 \%)$ & $80(11 \%)$ & \\
\hline Very good & 974 & $767(38 \%)$ & $206(30 \%)$ & \\
\hline Good & 840 & $599(30 \%)$ & $242(35 \%)$ & \\
\hline Fair/Poor & 400 & $234(12 \%)$ & $166(24 \%)$ & \\
\hline Age in years (median, quartiles) & $68(62,73)$ & $66(60,71)$ & $74(69,78)$ & $<0.001$ \\
\hline$<50$ & 45 & $45(2 \%)$ & $0(0 \%)$ & \\
\hline $50-69$ & 1,537 & $1345(67 \%)$ & $193(28 \%)$ & \\
\hline $70+$ & 1,113 & $611(31 \%)$ & $501(72 \%)$ & \\
\hline Race & & & & 0.70 \\
\hline White & 2,070 & $1545(77 \%)$ & $526(76 \%)$ & \\
\hline Black & 349 & $253(13 \%)$ & $95(14 \%)$ & \\
\hline Hispanic & 276 & $203(10 \%)$ & $73(10 \%)$ & \\
\hline Insurance & & & & $<0.001$ \\
\hline Medicare & 1,254 & $881(44 \%)$ & $372(54 \%)$ & \\
\hline Private/military & 1,194 & $936(47 \%)$ & $258(37 \%)$ & \\
\hline Medicaid/other/none & 47 & $27(1 \%)$ & $21(3 \%)$ & \\
\hline Unknown & 200 & $157(8 \%)$ & $43(6 \%)$ & \\
\hline Education & & & & 0.003 \\
\hline$<$ High school (HS) & 539 & $355(18 \%)$ & $184(26 \%)$ & \\
\hline HS/some college & 1,173 & $877(44 \%)$ & $296(43 \%)$ & \\
\hline College & 406 & $309(15 \%)$ & $97(14 \%)$ & \\
\hline Advanced degree & 544 & $433(22 \%)$ & $110(16 \%)$ & \\
\hline Unknown/refused & 33 & $27(1 \%)$ & $7(1 \%)$ & \\
\hline Marital status & & & & $<0.001$ \\
\hline Married/partnered & 2,150 & $1656(83 \%)$ & $494(71 \%)$ & \\
\hline Single & 522 & $328(16 \%)$ & $194(28 \%)$ & \\
\hline Unknown/refused & 23 & $17(1 \%)$ & $6(1 \%)$ & \\
\hline Employment & & & & $<0.001$ \\
\hline Working full-time & 617 & $542(27 \%)$ & $74(11 \%)$ & \\
\hline Working part-time & 260 & $205(10 \%)$ & $55(8 \%)$ & \\
\hline Retired & 1,699 & $1161(58 \%)$ & $540(78 \%)$ & \\
\hline Other/refused & 119 & $93(5 \%)$ & $25(3 \%)$ & \\
\hline PSA level (median, quartiles) & $7.8(5.4,13.1)$ & $7.5(5.3,12.0)$ & $9.3(5.9,21.1)$ & $<0.001$ \\
\hline$<4 \mathrm{ng} / \mathrm{mL}$ & 252 & $181(10 \%)$ & $70(10 \%)$ & \\
\hline $4-10 \mathrm{ng} / \mathrm{mL}$ & 1,381 & $1118(58 \%)$ & $263(38 \%)$ & \\
\hline$>10 \mathrm{ng} / \mathrm{mL}$ & 900 & $612(27 \%)$ & $289(42 \%)$ & \\
\hline Unknown & 162 & $90(5 \%)$ & $72(10 \%)$ & \\
\hline Gleason score & & & & $<0.001$ \\
\hline$\leq 6$ & 1,189 & $947(47 \%)$ & $241(35 \%)$ & \\
\hline$\overline{7}-10$ & 627 & $462(23 \%)$ & $166(24 \%)$ & \\
\hline Unknown & 879 & $592(30 \%)$ & $287(41 \%)$ & \\
\hline Comorbidity & & & & $<0.001$ \\
\hline 0 & 1,006 & $803(44 \%)$ & $203(29 \%)$ & \\
\hline 1 & 880 & $662(33 \%)$ & $218(31 \%)$ & \\
\hline 2 & 440 & $318(16 \%)$ & $121(18 \%)$ & \\
\hline $3+$ & 369 & $218(11 \%)$ & $152(22 \%)$ & \\
\hline Mortality outcomes & & & & $<0.001$ \\
\hline Alive & 1,506 & $1295(65 \%)$ & $211(30 \%)$ & \\
\hline Prostate cancer death & 263 & $146(7 \%)$ & $117(17 \%)$ & \\
\hline Other-cause death & 926 & $560(28 \%)$ & $366(53 \%)$ & \\
\hline
\end{tabular}

ADT androgen deprivation therapy, WW watchful waiting, PSA prostate-cancer specific antigen

*Weighted for oversampling younger, Hispanic, and black men 


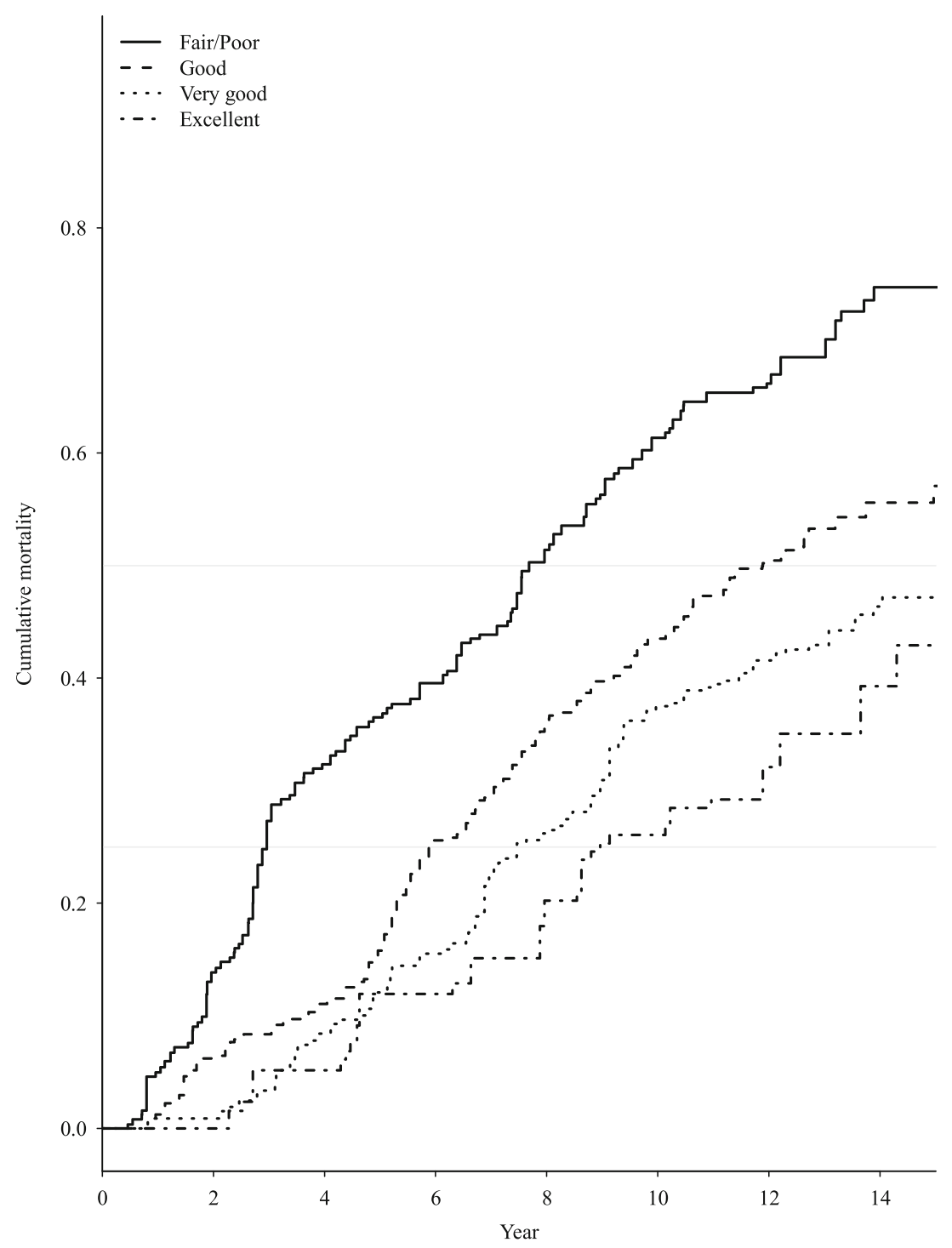

Figure 5. Competing risks cumulative incidence curve for other-cause mortality by initial self-reported health status in subjects who had not undergone surgery/radiotherapy at the time of reporting health status. 